\title{
Recycling of Beverage Containers in New Zealand: Critical Analysis of Existing Status and Proposed Best Practices
}

\section{Olufemi Omisakin ${ }^{*}$ and Jyoti Roy ${ }^{2}$}

${ }^{1}$ Nelson Marlborough Institute of Technology, New Zealand's University of Technology, New Zealand

${ }^{2}$ Nelson Marlborough Institute of Technology, Auckland Campus, New Zealand

*Corresponding author: Omisakin Olufemi, Nelson Marlborough Institute of Technology, New Zealands University of Technology, 42 Upper Queen Street, Eden Terrace, Auckland 1010, New Zealand, Tel: +64 9347 1342; E-mail: Olufemi.Omisakin@nmit.ac.nz

Received date: July 11, 2018; Accepted date: July 20, 2018; Published date: July 27, 2018

Copyright: (c) 2018 Omisakin O, et al. This is an open access article distributed under the terms of the Creative Commons Attribution License, which permits unrestricted use, distribution and reproduction in any medium, provided the original author and source are credited.

\begin{abstract}
Environment conservation is one of the primary concerns of most countries in the modern world because of the continuous increase in environmental degradation and the resulting pollution. Environmental pollution has become a major problem, as pollutants are indiscriminately dumped in the environment either intentionally or unintentionally. This activity often hampers balancing of the ecosystem leading to environmental issues.
\end{abstract}

Air, water, land and food can carry pollution caused by different human activities and leading to environmental pollution. Although pollution can be natural as well as man-made, man-made pollution is the most severe and threatens the existence of life on the planet.

The main causes of environmental pollution through human activities are emission of pollutants into the air from fuels used in transport, plastic and electronic dumping. The last two are problematic as it takes years for them to decompose. When pollutants are dumped into rivers and the sea, they constitute a danger to waterways and aquatic life; and closely related to this is dumping waste into water causing environmental pollution. This also constitutes a danger to aquatic ecosystems and living beings. Indiscriminate cutting of trees for economic purposes constitutes environmental pollution because it results in floods, destruction of biodiversity and climate change (global warming).

Improper dumping of beverage containers and disposable cups is one of the biggest contributors to growing environmental degeneration in modern cities. This study probes the problem of waste from beverage containers and its consequential effects on the New Zealand environment, and recommends some best practices for minimizing this waste.

Keywords Environment conservation; Environmental pollution; Electronic dumping; Global warming

\section{Introduction}

Many households in New Zealand produce large quantities of empty beverage containers and disposable cups, and in some cases, these are not properly disposed of, causing environmental hazards. Aside from natural causes, environmental pollution is mostly caused when nature decomposes, element dumped into it will do damage to itself or releasing hazardous side effects. This is typical because the element is not a natural component of nature. These elements are called pollutants. Toxic gases, plastic, metal, oil spills, chemicals from industrial waste, detergent chemicals, noise and paper waste are common pollutants. Pollution is creating health hazards for humans and leading to the extinction of many species. Active measures are being taken worldwide to check pollution and conserve the environment.

The study examines the status of waste from beverage containers from global and New Zealand perspectives. This assists the researcher to understand where New Zealand stands on the global platform on waste and recycling of beverage containers. The information obtained has helped the researcher examine some best practices of recycling and the culture of reusable cups and bottles through extensive use of the literature available on the subject in the form of journals, government documents and reports, industry stories, news and features on accredited channels, and the works of previous researchers.

Insights from the literature review are supported by primary research and analysis that validate the practicality of the best practices. These subsections are linked methodically to accomplish the objectives of the study, and to navigate the study to its conclusion where it answers the question of the proposal, i.e. whether these best practices seem rational to New Zealanders to curb beverage container's waste.

\section{Research objectives}

This study is driven by the researcher's interest in the need to protect the environment via continual advocating for environmental conservation and sustainability.

The objective of this study is to analyses systematically the waste from beverage containers in New Zealand, and some best practices that have produced results in other countries. From the assessment, recommendations can be adopted to control pollution from beverage containers in New Zealand. The scope of the study is limited to 
beverage container recycling and New Zealand to ensure that the research is streamlined, focused, comprehensible and informative.

\section{Limitations and ethics}

This study relies heavily on secondary data, and all efforts were made to ensure the secondary data used is reliable and valid.

For the primary data, the sample size has been limited to 60 respondents due to time and resource constraints. The survey results are the opinion of a small fragment population and cannot be considered as a representation of the whole population. The study is about beverage container waste in New Zealand but the survey sample is from Auckland residents, and again this may not be a good representation of the whole of New Zealand. Individual biases of the survey respondents also cannot be ruled out.

The questionnaire used for the survey did not require the respondents to disclose any personal data. Hence, the privacy or the survey participants are not exposed to any harm. The survey questionnaires filled out have been secure in confidentiality and are not accessible to anyone other than the author.

\section{Literature review}

In order to understand the necessity for recycling, it is imperative to gain an understanding of how damaging waste dumping is for our environment and life forms, including humans. The study has done this this by examining the three primary elements of the environment, water, land and air.

Under the Resource Management Act 1991 of New Zealand, land contamination has been defined as, "land that has a hazardous substance in or on it that has significant adverse effects on the environment; or is reasonably likely to have significant adverse effects on the environment' [1]. Landfills, which are the oldest system of waste disposal, are now being recognized as a serious threat to the environment, emitting a high percentage of greenhouse gases and contributing significantly to global warming. Landfills emit more than ten highly toxic gases. Methane is one of the most threatening and highly flammable of these gases, produced during the decaying process of organic matter. Methane has the potential of trapping solar radiation 20 times more than carbon dioxide, and as a result, global temperature is rising [2].

Apart from methane, other household, consumer, industrial and agricultural wastes that include large quantities of plastics, metals, glass and rubber find their way into landfills. Non-organic waste takes a very long time to decompose, and the decomposition process releases toxic gases that affect the air quality considerably. Air pollution is becoming one of the primary concerns for human health. Air pollution is ranked the 13th major cause of mortality worldwide, causing approximately 2 million premature deaths per year. In 2012, ambient air pollution caused 7 million deaths worldwide, including all types of air related illnesses. According to the World Health Organization (WHO), 6\% of air pollution related deaths are associated with lung cancer, $14 \%$ with acute respiratory infections and chronic obstructive pulmonary disorder, and $80 \%$ with strokes and ischemic heart disease [3]

Landfills are also becoming a major source of soil pollution. Pollutants enter the soil system from other sources such as industrial discharge, poor agricultural practices and volcanic eruptions. However, landfill leakage continues to be the primary source. The pollutants introduced into the soil reach living beings, including humans, directly or indirectly through irrigation water, manures and other soil alterations that affect significantly on the ecosystem. Toxic substances from contaminated soil can accumulate in crops, and enter the human physiological process through food grains, damaging human health severely [4].

Similar to the pollution of land and air, the marine environment has also been subject to pollution and its aftermath. As per UNESCO's Intergovernmental Oceanographic Commission (IOC), marine pollution is "The introduction by man, directly or indirectly, of substances into the marine environment (including estuaries) resulting in such deleterious effects as harm to living resources, hazards to human health, hindrance to marine activities including fishing, impairment of quality for use of seawater and reduction of amenities" [5]. Of the total marine area on earth, only about $4 \%$ remains pristine. The remaining $96 \%$ has been subject to the adversities of human activities, of which about $40 \%$ is highly polluted. Marine debris contributes significantly to marine pollution, plastic bottles and metal cans being a significant component of the debris. Much of the debris enters the water directly or indirectly through drains, rivers or creeks, or by being blown into the water, as well as from being trashed on the shores by humans. Marine animals are injured or die by either ingesting, or entangled in marine debris. Each year, about 100,000 marine mammals, including endangered species, are estimated to be killed by marine debris. Plastic debris clogs their digestive tracts, blocking food passage and causing subsequent death. Two sperm whales were washed off the coast of California in 2008 with an unbelievable amount of plastic debris in their [6]. Apart from damage to marine life, pollution is also causing the water level to rise at an alarming rate. Global warming is the effect of the earth's surface temperature rising. As a result, the water level is rising due to thermal expansion, melting of glaciers and ice caps, and melting of the Iceland mass from Greenland and Antarctica. The oceans absorb $80 \%$ of the additional heat in the earth's atmosphere. As the water heats up, it expands, raising the water level. Similarly, the warming of the earth's atmosphere and rising temperature due to greenhouse gas emissions is leading to the melting of glaciers, polar ice caps, and the ice shelves of Greenland and Antarctica, which is raising the sea level. According to Meyer et al oceans are expected to rise between 11-38 inches enough to submerge many cities along the east coast of the US. The worst situation estimated is rising of the sea level to 23 feet by meltdown of the Greenland ice sheets, enough to swamp London $[7,8]$.

If we review the above literature, the magnitude of the damage caused to the planet, the environment and the living species is incalculable. The literature also reiterates the fact that it is largely damage caused by humans, affecting humankind directly or indirectly. Plastic beverage containers and metal cans constitute a large portion of the waste generated by humans. Since it is destruction caused by humans and affecting human habitation, it is imperative that humans look for a solution. Understanding the impact of waste management, governments and organizations have taken initiatives to find long-term solutions that will eradicate the problem completely in the future and mitigate the immediate effects.

Recycling and reuse are effective ways of reducing waste from plastic bottles and metal cans. The process of recycling involves four major steps: collecting, separating, processing and marketing [9]. Plastic beverage containers are recycled and processed to manufacture clear film for packing and wrapping, rug fibers, raincoats, spools, rulers, video/CD covers, etc. Earlier, glass was more actively used to package beverages, but over the time it was replaced with plastic 
because of its un-breakability, ability to maintain beverage temperature longer and low weight qualities. Beverage bottles are largely recycled to manufacture new bottles or fiber applications. Super clean recycling processes based on depolymerization and partial-depolymerization is been developed over time for removal of contaminations and to push the recycling process. As the consumption of plastic bottles and their subsequent waste is increasing, so is the bottle-to-bottle recycling and manufacture [10].

Besides the industrial recycling of plastic containers, organizations and individuals are researching and developing innovative ways to use the plastic and metal can waste. In recent time eco-friendly road construction by means of recycling plastic are springing up, with the capacity to reduce carbon emission by one-third [11]. In India, more than 21,000 miles of road constructed out of recycled plastic. Most of the plastic road is in the southern state of Tamil Nadu, largely the rural areas, but also in the metropolitan cities of Mumbai and Chennai. These roads are stronger and more durable than conventional roads, held together by remarkably cheap polymer glue made from shredded plastic waste [12]. Roads developed from recycled plastic last for 35-50 years on average, compared with a lifespan of 2-18 years of for normal roads. Plastic roads reportedly have $10-15 \%$ lower road damage, smooth roads lead to $4.5 \%$ fuel savings and $15 \%$ lower energy consumption [13].

Plastic bottle waste is considered as an excellent source for building material. Plastic bottles are being used by companies and individuals world over to create architectural marvels or to provide basic shelter to the needy and homeless. The architecture wonder EcoARK in Taipei, Taiwan is one of the few initiatives in this direction. EcoARK is a ninestory structure, built from 1.5 million plastic bottles that cost US\$3 million. The building is powered by solar energy and is strong enough to survive calamities such as fire and earthquakes [14]. Similarly, a Colombian company has developed LEGO like building blocks, using shredded recycled plastic that can be used to construct homes by simply fitting the blocks together, with no construction experience or expertise required [15]. A basic standard home will take at most five days to construct if four people are working at it. These blocks are not only convenient to assemble; they are also fire and earthquake resistant, and surprisingly cost effective. The company started the development of the blocks to address two pressing issues predominant in Latin America, the need for housing for the growing urban population and the alarming amount of plastic content in the landfills [15].

As organizations and governments have taken steps towards recycling plastic bottles, there have been substantial initiatives towards recycling of beverage cans. There are companies world over that are actively involved in the manufacturing of products from recycled beverage cans, not only contributing towards environmental health, but also providing jobs and security. Hydro, a Norwegian company, has developed a US $\$ 53$ million facility at its Nuess plant in Germany, to recycle up to 50,000 tons of beverage cans. The company uses a new patent high tech design for sorting and separating different types of used metals, tailored for used beverage cans recycling, which makes the company a world leader in recycling of beverage cans. The used beverage cans are recycled and developed into new products for use such as new cans, building material, frames for automobiles, cycles, home appliances, electric wires, computer parts, etc. The recycling plant has created 40 new jobs, with a total work force of over 700 . Recycling of beverage cans will reduce 350,000 tons of carbon emission each year [16].
When analyzing the initiatives in recycling on a global level, it would not be improper to suggest that a solution to the problem of waste management lies in the problem itself. As Jorgensen rightly said, when free of their original content, beverage containers can be a problem or a resource - if trashed they can be a problem; if put into a system they can be a resource [17]. This powerful statement exemplifies converting a problem into an opportunity. This is not the responsibility alone of corporates and the government. The public as a whole plays the most important part in creating this waste, so their contribution towards resolving the problem is vital.

An overview of the state of waste contribution by beverage containers at global level and within New Zealand will help direct the study towards recycling best practices worldwide, and how they may be implemented in New Zealand, and the contribution of New Zealanders to the recycling process.

\section{Beverage containers waste-global overview}

Twenty years back, in 1996, the total dump of aluminium cans, glass and plastic bottles was 78 billion. This volume increased by 75 billion in 2010 to 153 billion cans and bottles ending up in litter streams and landfills [18].

The sale of plastic drinking bottles grew from about 300 billion ten years back to 480 billion in 2016. Less than half of these were collected for recycling. Only $7 \%$ of the collected volume was turned into new bottles [19]. In 2016, the recycling rate of plastic bottles in the U.S. was recorded as low as $23 \%$ of the total 50 billion bottles used, i.e. over 38 billion plastic bottles were dumped into the ocean or landfill [20]. The same year, more than 16 million plastic bottles ended up in landfill, ocean or being burnt in the UK every day, which is about half of the 38.3 million sold [21]. This analysis shows the trends in the growth of empty beverages cans that require a proper dumping system.

Every year about 1.5 million tons of aluminium cans are trashed worldwide. Less than half of over 100 billion aluminium cans sold in the US every year are recycled. The volume of trashed cans is replenished with new cans made from raw material. We need to be aware that apart from the hazards caused by the dumping of aluminium cans indiscriminately, manufacturing new cans damages the environment through emission of toxic gases. In general, production of new cans from raw material to replace about a ton of trashed cans accounts for over $14 \%$ of toxic gases emission [22].

Used disposable cups also contribute to environmental pollution like the beverage containers. In 2015, over 2.5 billion disposable cups were dumped in landfill sites in the UK, and about 2.8 billion in Germany [23]. Olorunshola asserted that only $1 \%$ of the 4.3 billion disposable cups used yearly in France is recycled [24]. According to Fine, an estimated 1 billion disposable cups are used annually and $90 \%$ of these end up in landfill, amounting to about 60,000 kilograms of plastic waste yearly [25]. Frater argues that in 2013, 50 billion disposable cups were trashed in landfill, enough to cover five times the back and forth distance between the earth and the moon [26].

These statistics give a very grim picture of the magnitude of environmental pollution by beverage containers. It is all the more worrying since this is the status of some of the most progressive countries in the world that have high literacy rates to inculcate more awareness and with strong economies to invest fittingly in recycling and sustainability systems. It is quite difficult to calculate the quantity of waste from beverage containers generated by developing and under- 
developed countries would be, given the lack of awareness, low literacy rates and most importantly, no or weak environment protection laws.

Though environmental damage is increasing at an alarming rate as pollution levels are at all-time high, it is not completely a lost cause. There is a growing awareness world over, through increasing media reach and social media exposure. Saving the environment has become a global cause amongst governments and citizens alike. Some countries are setting an example by becoming zero waste nations. These countries have successfully developed and put into force waste management policies that has not only made them cleaner and healthier countries but have also generated wealth for them. European Union countries collectively recorded a recycling rate of $71.3 \%$ in 2013 , heading steadily towards the $80 \%$ target by 2020 [27]. Countries like Germany, Norway, Finland, Denmark, Netherlands, Sweden, Switzerland, and Austria are leading the way in recycling and sustainability. Germany alone recycled 83,500 tons of aluminium packaging in 2012, which is over $89 \%$ of the total aluminium packaging produced that year [28]. In 2015, Germany recycled $93.5 \%$ of plastic bottles [29]. Similarly, Norway recycled $97 \%$ of the 600 million plastics used in 2016 [30]. In 2011, Finland had achieved a recycling rate of $96 \%, 94 \%$ and $93 \%$ for cans, bottles, and paper respectively [31].

Initiatives from some relatively smaller countries have got world attention over effective recycling. Taiwan and South Korea are two such countries that have achieved laudable recycling rates over the past two decades. Taiwan's recycling rate grew from a mere 5.87\% in 1997 to over $60 \%$ in 2011 , owing to some great initiatives by the Taiwanese government [32]. Likewise, South Korea managed to recycle around $54 \%$ and incinerate $38 \%$ of total plastic waste, with only $8 \%$ going to landfills in 2010 [33].

\section{Beverage containers waste-new zealand overview}

Beverage container waste in some of the most progressive countries in the world and the initiatives towards effective recycling are good indicators to measure where New Zealand stands. In New Zealand, over 1 billion beverage containers are disposed of in litter, streams, waterways or landfills each year, where on an average 2.2 billion beverage cans and bottles are used annually. Currently, at $40 \%$, New Zealand's beverage container recycling rates are embarrassingly low compare with progressive countries like Canada, South Australia and many countries within Europe [34]. According to Auckland Council statistics, an average Aucklander contributes about $160 \mathrm{~kg}$ landfill dump every year, when $65 \%$ of this waste could have been recycled [35].

Given the size of New Zealand and the small population of about 4.8 million people (Statistics New Zealand, 2017), waste management can be a lot more effective. However, there are not many initiatives in this direction, and neither are there many recycling processing facilities in the country. There are public waste bins; in some places there is a single bin for all types of wastes, and some places where there are two or three bins for different waste types. This is not good enough to improve the recycling rate of the country.

\section{Best practices}

The study has established through statistics that some countries are on the way to achieving zero waste targets using some very effective and convenient systems. The study explores some of these best practices.

\section{Discount on reusable cups/bottles and charges on disposable cups}

Discount on purchasing beverages using reusable cups is a common practice among cafes in Europe, US, Canada, and Australia. The cafes voluntarily extend the discount, and the consumers benefit from the discount while also making their individual contribution towards reducing beverage cups waste.

Contrasting the discount scheme is the system of levying additional charges on the use of disposable cups. This system encourages consumers to use reusable beverage cups/bottles. Alarmed by the rising waste of disposable cups. Countries like UK and Germany plan to introduce the system as a mandatory policy. A study by the Environmental Audit Committee of UK government revealed that though some cafes offer discounts for reusable cups, only $1-2 \%$ of customers avail themselves of the offer. The committee suggested that consumers respond better to charges than to discounts as proved by the use of plastic bags going down by $83 \%$ since the policy of charges on plastic bags was introduced. They expect charges on disposable cups will bring down the use by 50-300 million per year [36]. However, the researcher felt that one or both of these systems could benefit New Zealand to bring down the disposable cups waste, which is currently at 295 million annually. However, the acceptability and success of either of the two options by consumers will depend on how it is marketed by the concerned body.

\section{Levy and deposit scheme}

When a product packaging is returned for recycling, the consumer is given an incentive which is a combination of the tax and rebate on the product [37]. It is one of the most successful systems of recycling, where a consumer gets an incentive/refund for returning bottles and cans for recycling. This system is behind the zero waste success stories of countries like Germany, Norway, Finland, Sweden, Switzerland, UK, Ireland, Canada, Australia and even Taiwan and South Korea. The ageold levy and deposit system in Finland reported return rates of $90 \%$ in 2015, making it one of the most recycling enabled countries in the world [38]. Some countries have vending machines that dispense refund money upon deposit of cans/bottles; others have designated shops and outlets where a consumer can deposit cans/bottles and collect refund money. This system has not only improved the recycling rates in the countries that follow it, it has also generated jobs in these countries.

\section{Customized branded reusable cups/bottles}

This calls for voluntary participation from organizations. Customized reusable cups/bottles with company logo, is been widely and successfully used as an effective system to reduce the use of disposable cups, and a great marketing tool. The culture of giving branded reusable cups to employees, vendors, shareholders, stakeholders and corporate partners as a corporate social responsibility exercise has also proved to be an excellent branding exercise. Schools/ Colleges/Universities can adopt the system too.

\section{Incorporate waste management in induction programmes}

During the course of research of secondary data, the researcher came across literature that revealed that a lot of waste is created because of lack of awareness among the population. According to a recent report by Reidy [39], millions of beverage cups end up in landfill and streams every year in New Zealand because of confusion and lack 
of clarity over the waste management sector. The researcher is of the opinion that incorporating a module on waste management in the induction programmes of companies, schools, colleges, and universities would go a long way in educating the population on what are recyclable wastes, how they can be manage and recycled and what the different types of waste bins are meant for.

\section{Materials and Methods}

Hawkins asserted that law becomes operative and beneficial only when human judgment accepts it, reconciling all conflicts, and is determined to apply it. According to him the willingness of human judgment, makes a law impactful. This study believes that reduction of pollution caused by beverages and disposable cups in New Zealand requires major involvement of government through establishment of viable policies and laws [40].

Understanding the role of citizen participation in any government policy/law to minimize beverage container waste prompted the researcher to embark on primary research using a survey questionnaire, to gauge the outlook of New Zealanders towards such systems. The study also evaluates the level of awareness of recyclable waste and the signs/indicators on public waste bins.

The survey, using the Stratified Sampling Method with a sample size of 60 people between the age groups of 15-60 years, indicated that the general awareness regarding recyclable waste among people is quite low. As seen in Figure 1, only 18 out of 60 respondents thought the signs on public waste bins were clear enough to indicate what type of waste they are meant for, while a high number of 38 respondents felt otherwise.

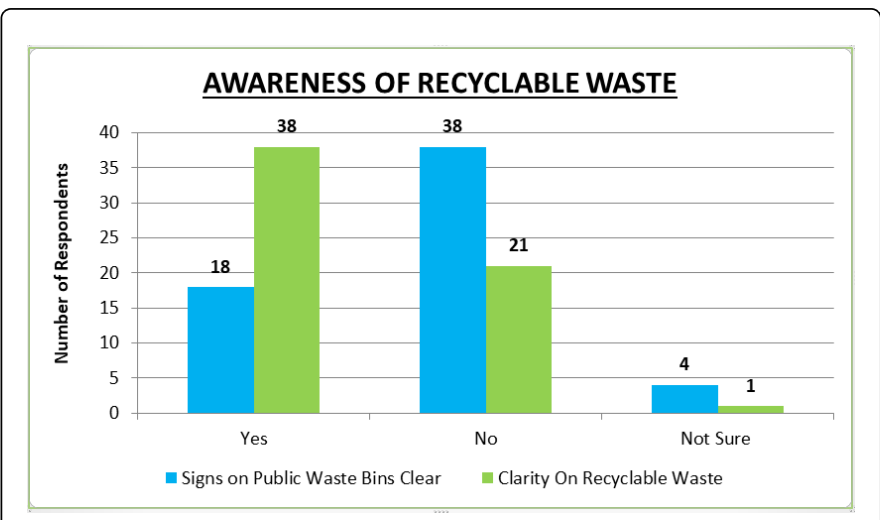

Figure 1: Survey result indicating public awareness of the signs/ indicators on waste bins and recyclable waste.

The survey also brought to light that a large population is not aware of what recyclable waste is, and how to differentiate it from other forms of waste. As clearly shown in Figure 1, only 38 respondents are clear on the subject, and the rest about $35 \%$ are not clear.

The same group of respondents was asking for their opinion on the effectiveness of some pf the best practices discussed in the literature review. It is not surprising that 57 out of 60 , i.e. $95 \%$ of the respondents support the idea of including a module on waste management in the induction programmes of company/schools/colleges/or universities to educate people about recycling and sustainability, as shown in Figure 2. The figure also shows 54 participants agreed that a refund/incentive for returning bottles and cans is a good way of encouraging people to recycle beverage containers. 51 participants agreed that providing a discount on purchasing beverages in reusable cups/bottles will work well but the support for additional charges on disposable cups was relatively low at 58\% (35 respondents). 17 respondents are of the opinion that the system of additional charges on disposable cups will not be well accepted while 8 participants were not sure. Give-away of company/institute branded reusable cups/bottles to students, employees, stakeholders, vendors and clients will not only support the cause of reducing beverage container waste; it is also a great marketing exercise favoured by 47 participants.

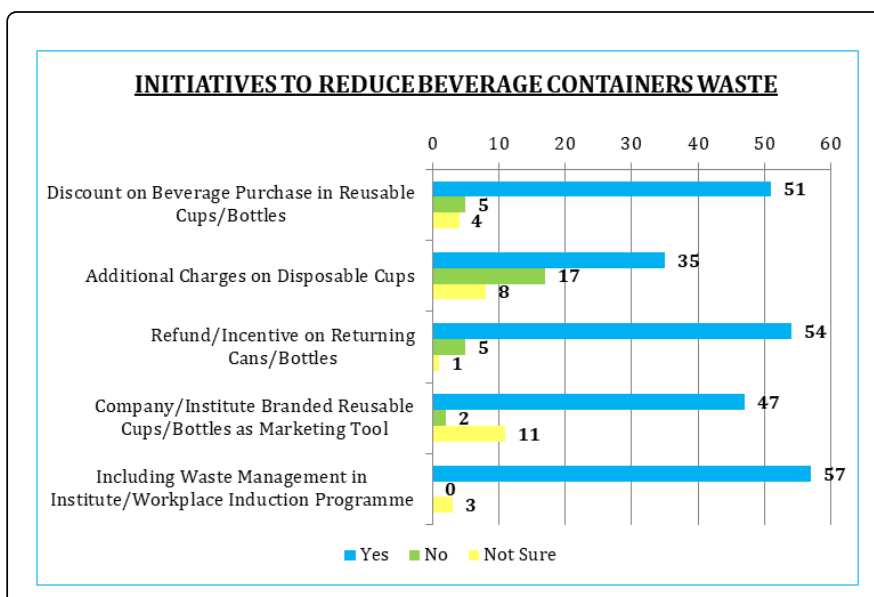

Figure 2: Survey result indicating public support on suggested initiatives to reduce beverage container waste.

Sources: Primary Survey Questionnaire

\section{Result and Discussion}

The primary research backed by the literature review will assist the study to reach a logical and fair conclusion once the methodology and limitations is been discussed. Given the nature of the study, both secondary and primary data is been used to establish the objectives of the study and to arrive at a logical and valid answer to the research question of the proposal-whether the suggested best practices to reduce beverage container waste are viable options.

Secondary data is been collected extensively from government datasets, journals, industry articles, relevant websites, accredited news media and the study of previous researchers to ensure utmost reliability and validity of the data. Two datasets is been constructively used to derive a linear relationship between waste generated by beverage containers and recycling and management of beverage containers. Since the information required facts and figures to establish the objectives, secondary data has been meticulously evaluated because of the validity of the source such as government documents and data, or news channels like the $\mathrm{BBC}$, government websites, journals and previous research work.

The secondary data is supported by primary research data that validates the information generated through secondary research data. Primary research is been conducted through a questionnaire using Stratified Sampling Method and analyzed to ensure the data source, as well as the outcome, are reliable and free of biases. The Stratified Sampling Method has been used as a wide range of age groups from 15-54 years has been sampled, breaking them into subgroups of 15-24, 
25-34, 35-44, 45-54 years. This method is use as wide range of age groups consumes beverages, and the intent was to allow equal participation from each age group. The objective of the survey is to gauge the population's understanding of recyclable waste and their consensus on proposed methods to encourage recycling and use of reusable cups/bottles. The secondary and primary data have been critically analyzed to link the research to the objectives and the outcome of the research.

\section{Conclusion}

The recycling rate of beverage containers in New Zealand continues to be at a low $40 \%$, lagging way behind other progressive countries. Countries like Germany, Finland, Norway and Sweden have successfully achieved a recycling rate of $90-95 \%$ for beverage containers using effective systems that can be considered for replication in New Zealand.

The study examines these systems and their effectiveness through secondary data research. The study reveals that refund/incentive on returning cans and bottles have worked very well for most countries. The study also shows that in most of these countries, coffee shops voluntarily offer discounts on purchase of beverages in reusable cups. Some countries like UK and Germany are planning to impose mandatory charges on the use of disposable cups to encourage the use of reusable cups. The study recommends practices like incorporating waste management in company/institute induction programmes and company/institute branded reusable cups and mugs for employees/ students. These cups may also be an excellent branding exercise 11 .

Primary data through a questionnaire survey of 60 participants showed $90-95 \%$ of the respondents supported systems of a discount on reusable cups, a refund on returning cans/bottles and inclusion of waste management in induction programmes. A great percentage of respondents also agreed that charges on disposable cups and branded reusable cups/bottle are sound initiatives.

The study recommends that comprehensive and extensive research be carried out on recycling of beverage containers in New Zealand. The recommended study should cover all regions of New Zealand for easy generalization and acceptability.

\section{References}

1. New Zealand Legislation (1991) Resource Management Act 1991 No 69 (as at 27 June 2018), Public Act 2 Interpretation-New Zealand Legislation.

2. Conserve Energy Future (2017) Causes, Effects and Solutions of LandfillsConserve Energy Future.

3. Weeberb JR, Matthew AD, Altaf A, Stefania P, Petros K, et al. (2018) Global Association of Air Pollution and Cardiorespiratory Diseases: A Systematic Review, Meta-Analysis, and Investigation of Modifier Variables 108: S123-S130.

4. Meyer L, Brinkman S, Van Kesteren L, Leprince-Ringuet N, Boxmeer F (2015) Climate Change Synthesis report, Intergovernmental Panel on Climate Change.

5. Hassan D (2017) Protecting the marine environment from land-based sources of pollution: Towards effective international cooperation.

6. Weis JS (2015) Marine Debris: In Marine pollution: What everyone needs to know. New York: Oxford University Press pp: 46-49.

7. Meyer L, Brinkman S, Van Kesteren L, Leprince-Ringuet N, Boxmeer F (2015) Climate Change Synthesis report, Intergovernmental Panel on Climate Change.

8. National Geographic (2017) Sea Level Rise.
9. Shent H, Pugh R, Forssberg E (1999) A review of plastics waste recycling and the flotation of plastics. Resources, Conservation and Recycling 25: 85-109.

10. Welle F (2011) Twenty years of PET bottle to bottle recycling-An overview. Resources, Conservation and Recycling 55: 865-875.

11. Keijzer EE, Leegwater GA, de Vos-Effting SE, de Wit (2015). Environmental Science and Policy. In Carbon footprint comparison of innovative techniques in the construction and maintenance of road infrastructure in The Netherlands (p. 54).

12. Subramanian S (2016) Plastic roads: India's radical plan to bury its garbage beneath the streets.

13. Sojobi AO, Nwobodo SE, Aladegboye OJ (2016) Recycling of polyethylene terephthalate (PET) plastic bottle wastes in bituminous asphaltic concrete 3 .

14. Wang L (2017) Amazing building made from 1.5 million plastic bottles withstands fires and earthquakes.

15. Cooke L (2016) These LEGO-like recycled plastic bricks create sturdy homes for just $\$ 5,200$.

16. CanTech International (2016) The best place for used beverage cans?

17. Jorgensen FA (2011) Making a green machine: The infrastructure of beverage container recycling. New Brunswick, NJ: Rutgers University Press.

18. Container Recycling Institute (2011) All About Beverage Container Waste.

19. Laville S, Taylor M (2017) A million bottles a minute: World's plastic binge as dangerous as climate change.

20. Chow L (2017) 1 Million Plastic Bottles Bought Every Minute, That's Nearly 20,000 Every Second.

21. Taylor M (2018) A million bottles a minute: World's plastic binge as dangerous as climate change.

22. West L (2017) Aluminum recycling saves energy and enhances community life. The Benefits of Aluminum Recycling.

23. Germany trials reusable coffee cups (2016)

24. Olorunshola Y (2016) France Is the First Country to Ban Plastic Cups, Plates, and Cutlery.

25. Whyte $S$ (2016) Takeaway coffee cups piling up in landfill.

26. Frater J (2014) This paper cup can be recycled.

27. European Aluminium (2017) Great news for Aluminium beverage can recycling at new record high.

28. European Green Capital (2014) European Green Capital.

29. Waste Management World (2016) Bottle Deposits Responsible for High PET Recycling Rate in Germany.

30. Harrabin R (2018) UK 'could adopt' Norway recycling system.

31. Weaver $\mathrm{F}(2015)$ Finnish families get to grips with trash-this is FINLAND.

32. Diplomat T (2013) Taiwan's Recycling Boom: A Shining Example for Asia, the World.

33. Vink T (2014) Plastic Recycling in Korea - Improving Efficiency Through Technology Solutions | ASIA TODAY News and Events.

34. Snow W (2015) The incentive to recycle: A container deposit system for New Zealand. Retrieved from Envision New Zealand.

35. Auckland Council (2017) Make the Most of Waste.

36. Laville S (2018) MPs call for 25p charge on takeaway coffee cups ahead of possible ban.

37. Walls M (2011) Deposit-Refund Systems in Practice and Theory. SSRN Electronic Journal 11-47.

38. Fraane A, Stenmarck A, Gislason S, Lyng KA, Lokke S, et al (2014) Collection and recycling of plastic waste: Improvements in existing collection and recycling systems in the Nordic countries.

39. Reidy M (2018) Confusion sends millions of compostable coffee cups to landfill.

40. Hawkins K (1993) Environment and enforcement: Regulation and the social definition of pollution Oxford: Clarendon Press pp: 14. 